\title{
Validation of a Survival Score for Patients Receiving Radiosurgery or Fractionated Stereotactic Radiotherapy for 1 to 3 Brain Metastases
}

\author{
DIRK RADES ${ }^{1,2}$, OLIVER BLANCK ${ }^{3}$, MAI TRONG KHOA $^{2,4}$, PHAM VAN THAI ${ }^{4}$, \\ NGUYEN QUANG HUNG ${ }^{4}$, LIESA DZIGGEL ${ }^{1}$ and STEVEN E. SCHILD ${ }^{5}$ \\ ${ }^{1}$ Department of Radiation Oncology, University of Lübeck, Lübeck, Germany; \\ ${ }^{2}$ Faculty of Medicine, Hanoi Medical University, Hanoi, Vietnam; \\ ${ }^{3}$ Saphir Radiosurgery Center Northern Germany, Güstrow, Germany; \\ ${ }^{4}$ Nuclear Medicine and Oncology Center, Bach Mai Hospital, Hanoi, Vietnam; \\ ${ }^{5}$ Department of Radiation Oncology, Mayo Clinic, Scottsdale, AZ, U.S.A.
}

\begin{abstract}
Background/Aim: We developed a scoring system to predict 1-year survival after radiosurgery for 1-3 brain metastases. This study aimed to validate this system. Patients and Methods: Seventy-six new patients were included in this validation study. Like in the original scoring-system, three factors (age, performance status, extra-cranial metastases) were used. For each factor, 1-year survival rates in \% were divided by 10, and the three scoring-points were added for each patient. Results: Patient's scores were 10, 11, 13, 14, 16 or 17 points with 1-year survival rates ranging between $31 \%$ and $80 \%$. Two groups, $10-14$ and $16-17$ points were formed. In the 14-16 points group, 1-year survival was $47 \%$ (versus $33 \%$ in the preceding study, $p=0.060$ ). In the 16-17 points group, 1-year survival rates were $75 \%$ versus $77 \%$ $(p=0.79)$. Conclusion: In the more favorable group, the scoring-system was very reproducible. In the less favorable group, the difference was larger, but also not signficant.
\end{abstract}

Two randomized trials compared radiosurgery alone to radiosurgery combined with whole-brain radiotherapy (WBRT) for very few brain metastases. Both found that the addition of WBRT had a negative impact on neuro-cognitive function $(1,2)$. Therefore, omitting WBRT has become more

This article is freely accessible online.

Correspondence to: Prof. Dirk Rades, Department of Radiation Oncology, University of Lübeck, Ratzeburger Allee 160, 23562 Lübeck, Germany. Tel: +49 45150045400, Fax: +49 45150045404, e-mail: rades.dirk@gmx.net

Key Words: Radiosurgery, fractionated stereotactic radiotherapy, brain metastases, survival, scoring-system, validation. popular. However, on the other hand, several studies showed that WBRT resulted in significantly better intracerebral control (1-4). And one has to be aware that progressive or new brain metastases have also be associated with neurocognitive decline $(4,5)$. Thus, patients with a high risk of developing new brain metastases or experience a progression or recurrence of the treated lesions may benefit from the addition of WBRT.

Furthermore, the increasing use of novel systemic treatments such as targeted therapies prior, during or after radiotherapy may lead to improved survival but may also damage brain tissue not affected by metastatic disease $(5,6)$. Thus, the treatment of a very limited number of brain metastases has become more complex recently and requires more personalized treatment regimens. Such a personalized treatment approach should always consider a patient's survival prognosis, which has been suggested for other metastatic situations (7-14). In order to facilitate the selection of the appropriate treatment regimen for a patient who is supposed receiving radiosurgery or fractionated stereotactic radiotherapy (FSRT) alone for a very limited number of brain metastases, a scoring-system that allows the physician to quickly estimate a patient's remaining survival time is helpful. We have developed such a scoring-system about three years ago (15). However, this system has not yet been validated. The present study was conducted to assess the validity and reproducibility of the previously developed scoring-system.

\section{Patients and Methods}

The data of 76 new patients treated with single-fraction radiosurgery alone $(n=50)$ or FSRT alone $(n=26)$ for 1 to 3 brain metastases from a solid tumor were retrospectively analyzed. The characteristics of these patients are summarized in Table I. Of this cohort, 41 patients were treated with a linear accelerator and 35 patients with a 
Cyberknife ${ }^{\circledR}$. In case of single-fraction radiosurgery, doses ranged from 16 to $25 \mathrm{~Gy}$. The most frequent dose was $20 \mathrm{~Gy}$, which was administered in 33 of the 50 patients $(66 \%)$, followed by $18 \mathrm{~Gy}$, given in 13 patients (26\%). In case of FSRT, 16 patients received 3 fractions of 7-11 Gy, 8 patients received 5 fractions of 5-8 Gy and 2 patients received 6 fractions of $5 \mathrm{~Gy}$, respectively.

The present series served as a validation cohort for a scoringsystem previously developed to predict the 1-year survival probability of patients receiving radiosurgery alone for 1 to 3 brain metastases (15). On the multivariate analysis of the previous study, three factors were found to be significantly associated with survival. These factors were age at the time of radiotherapy ( $\leq 60$ versus $\geq 61$ years), Eastern Cooperative Oncology Group (ECOG) performance score (0-1 versus 2$)$ and extra-cranial metastases (no versus yes) (12). For each of these three factors, the 1-year survival rates in $\%$ were divided by 10 , and subsequently, the three scoring-points were summed to generate the prognostic score for a specific patient. In the present validation study, the same procedure was used to obtain the prognostic score for each patient. The survival analyses were performed with the Kaplan-Meier method, and the Kaplan-Meier curves were compared with the Wilcoxon test (16). Significance was defined as a $p$-value of $<0.05$, a trend as a $p$-value of $<0.10$.

\section{Results}

The scores for individual patients were $10,11,13,14,16$ or 17 points. These scores were associated with 1-year survival rates of $31 \%, 45 \%, 33 \%, 54 \%, 67 \%$ and $80 \%$, respectively $(p=0.009)$. Based on these data, two prognostic groups, i.e. 1014 points and 16-17 points, were formed. The 1-year survival rates of these groups were $47 \%$ and $75 \%$, respectively ( $p=0.099$, Figure 1). The corresponding 1-year survival rates in the previous cohort used for developing the scoring-system were $33 \%$ (10-14 points) and $77 \%$ (16-17 points), respectively $(p<0.001)(15)$. In addition, the survival data of the favorable groups (16-17 points) of the previous and the current study were compared. So were the survival data of the less favorable groups (10-14 points) in order to further investigate the reproducibility of the scoring-system. In the 14-16 points group, the 1-year survival rates were $47 \%$ in the current study versus $33 \%$ in the preceding study $(p=0.060)$. In the $16-17$ points group, the 1-year survival rates were $75 \%$ versus $77 \%(p=0.79)$.

\section{Discussion}

A considerable number of patients presenting with a very limited number of brain metastases are treated with radiosurgery or FSRT, which were shown to be more costeffective than neurosurgery $(17,18)$. Radiosurgery either alone or combined with WBRT can lead to excellent long-term results (19). During recent years it has become increasingly popular to administer radiosurgery or FSRT alone rather than combining these approaches with WBRT. This was due to the results of two randomized trials $(1,2)$. One of these trials included 58 patients. Radiosurgery alone was associated with significantly less impairment of neuro-cognitive function than radiosurgery supplemented by WBRT at 4 months following treatment ( $24 \%$ versus $52 \%$ ) (1). In the other trial, neurocognitive deficits at 3 months following treatment was observed in $64 \%$ and $92 \%$ of patients, respectively $(p<0.001)$ (2). Another important finding from the first trial was that the 1-year intracerebral control rates were only $27 \%$ after radiosurgery alone compared to $73 \%$ after radiosurgery plus WBRT $(p<0.001)(1)$. These results agree with those of a third randomized trial reporting 1-year intracerebral control rates of $24 \%$ and $53 \%$, respectively $(p<0.001)$ (4). However, improvement of intracerebral control did not translate into improved survival $(1,4)$. Therefore, many treating physicians feel that the omission of WBRT is justified in case of a very limited number (mainly 1-3 lesions) of brain metastases. WBRT appears to improve control in the brain but impairs quality of life and doesn't improve survival.

However, one may speculate that a considerable proportion of patients with 1-3 brain metastases might benefit from the addition of WBRT to radiosurgery or FSRT. In order to provide the appropriate treatment regimen for an individual patient, it would be important to be able to estimate the patient's risk of developing new brain metastases and the patient's remaining lifespan. Several scoring tools have already been reported that help judge the risk of developing new brain lesions (20-23). We have also developed a scoring-system particularly for patients treated with radiosurgery alone for 1-3 brain metastases that enabled the treating physicians to estimate a patient's 1-year survival probability (15). This system was based on three factors significantly associated with survival, namely age, performance score and extra-cranial spread. It was the first scoring-system for patients receiving linear-accelerator based radiosurgery alone. Scoring points ranged from 10 to 17 , and two survival groups were created with 1-year survival rates of $33 \%$ (10-14 points) and 77\% (16-17 points), respectively (15). However, the scoring-system has not yet been validated. Therefore, the present study was performed including 76 new patients treated with radiosurgery or FSRT alone for 1-3 brain metastases. In this study, the 1-year survival rates were $47 \%$ and $75 \%$, respectively. The intergroup comparisons between both studies revealed that the findings in the 16-17 points group were very similar and could, therefore, be considered valid and well reproducible. In the 10-14 points group, the 1-year survival rate in the present study was $14 \%$ higher than in the previous study. This finding may be a consequence of improved systemic treatments (6). However, the difference regarding the 1-year survival rate between the two prognostic groups in the current study still showed a trend and would likely be significant if the number of patients $(n=76)$ was as high as in the previous study $(n=214)$. Therefore, the scoring-system may be considered valid to a certain extent also in the $10-14$ points group. However, it becomes obvious that due to improvement of anticancer treatments, survival scores need to be updated in appropriately large patient cohorts from time to time. 
Table I. Characteristics of the validation cohort $(n=76)$.

\begin{tabular}{lc}
\hline & $\begin{array}{c}\text { Distribution } \\
\text { of patients } \\
\text { N }\end{array}$ \\
& \\
Age & 34 \\
$\leq 60$ Years & 42 \\
$\geq 61$ Years & \\
Gender & 34 \\
Female & 42 \\
Male & \\
Primary tumor type & 15 \\
Breast cancer & 23 \\
Non-small cell lung cancer & 9 \\
Melanoma & 29 \\
Other tumors & \\
ECOG performance score & 55 \\
$0-1$ & 21 \\
2 & \\
Number of cerebral lesions & 43 \\
1 & 33 \\
$2-3$ & \\
Extra-cranial metastases & 29 \\
No & 47 \\
Yes & \\
Interval from cancer diagnosis to & \\
radiotherapy of brain metastases & \\
$>15$ Months & \\
$>15$ Months & 31 \\
\hline
\end{tabular}

In the $16-17$ points group, $75 \%$ of the deaths were due to new brain metastases outside the irradiated areas and not to extra-cranial spread. Therefore, the addition of WBRT to radiosurgery or FSRT should be considered. Systemic treatment may be postponed until extra-cranial spread occurs. In contrast, in the $10-14$ points group $50 \%$ of deaths were due to extra-cranial metastases and systemic treatment should be strongly considered and administered early. When following these suggestions, the retrospective nature of both studies must be considered.

In conclusion, in the more favorable group (16-17 points), the scoring-system proved to be valid and well reproducible. In the less favorable group, the 1-year survival was nonsignificantly better than in the previous study, which was most likely due to improved systemic treatments including modern targeted therapies. Thus, the scoring-system can be used to estimate the 1-year survival probability of patients assigned to radiosurgery or FSRT alone for 1-3 brain metastases.

\section{Conflicts of Interest}

On behalf of all Authors, the corresponding Author states that there is no conflict of interest related to this study.

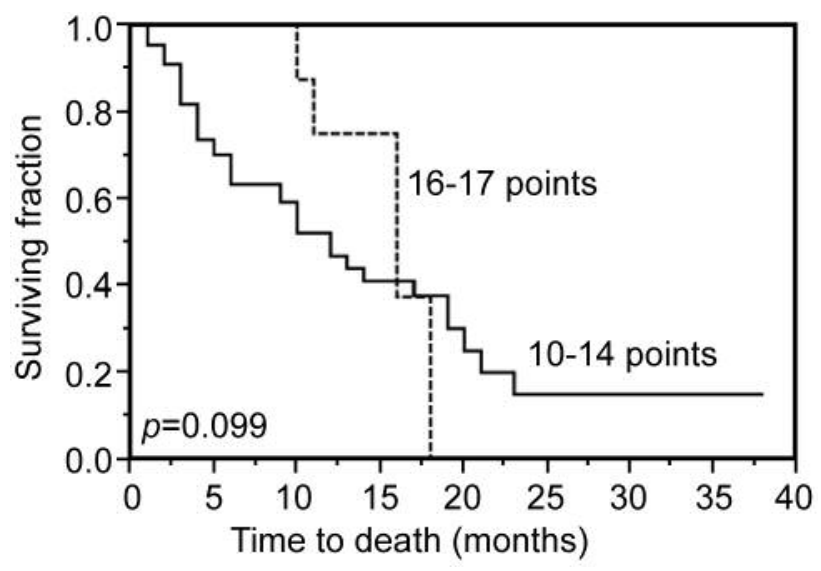

Figure 1. Comparison of the two prognostic groups (10-14 versus 1617 points) for survival.

\section{References}

1 Chang EL, Wefel JS, Hess KR, Allen PK, Lang FF, Kornguth DG, Arbuckle RB, Swint JM, Shiu AS, Maor MH and Meyers CA: Neurocognition in patients with brain metastases treated with radiosurgery or radiosurgery plus whole-brain irradiation: a randomised controlled trial. Lancet Oncol 10: 1037-1044, 2009.

2 Brown PD, Jaeckle K, Ballman KV, Farace E, Cerhan JH, Anderson SK, Carrero XW, Barker FG 2nd, Deming R, Burri SH, Ménard C, Chung C, Stieber VW, Pollock BE, Galanis E, Buckner JC and Asher AL: Effect of radiosurgery alone vs radiosurgery with whole brain radiation therapy on cognitive function in patients with 1 to 3 brain metastases: A randomized clinical trial. JAMA 316: 401-409, 2016.

3 Rades D, Huttenlocher S, Hornung D, Blanck O and Schild SE: Radiosurgery alone versus radiosurgery plus whole-brain irradiation for very few cerebral metastases from lung cancer. BMC Cancer 14: 931, 2014.

4 Aoyama H, Shirato H, Tago M, Nakagawa K, Toyoda T, Hatano K, Kenjyo M, Oya N, Hirota S, Shioura H, Kunieda E, Inomata $\mathrm{T}$, Hayakawa $\mathrm{K}$, Katoh $\mathrm{N}$ and Kobashi $\mathrm{G}$ : Stereotactic radiosurgery plus whole-brain radiation therapy vs. stereotactic radiosurgery alone for treatment of brain metastases. A randomized controlled trial. JAMA 295: 24832491, 2006.

5 Tsao MN, Rades D, Wirth A, Lo SS, Danielson BL, Gaspar LE, Sperduto PW, Vogelbaum MA, Radawski JD, Wang JZ, Gillin MT, Mohideen N, Hahn CA and Chang EL: Radiotherapeutic and surgical management for newly diagnosed brain metastasis(es): An American Society for Radiation Oncology evidence-based guideline. Pract Radiat Oncol 2: 210-225, 2012.

6 He Q, Bi X, Ren C, Wang Y, Zou P, Zhang H, Chi N, Xiu C, Wang Y and Tao R: Phase II study of the efficacy and safety of high-dose pemetrexed in combination with cisplatin versus temozolomide for the treatment of non-small cell lung cancer with brain metastases. Anticancer Res 37: 4711-4716, 2017. 
7 Dziggel L, Segedin B, Podvrsnik NH, Oblak I, Schild SE and Rades D: Validation of a survival score for patients treated with whole-brain radiotherapy for brain metastases. Strahlenther Onkol 189: 364-366, 2013.

8 Rades D, Dziggel L, Nagy V, Segedin B, Lohynska R, Veninga T, Khoa MT, Trang NT and Schild SE: A new survival score for patients with brain metastases who received whole-brain radiotherapy (WBRT) alone. Radiother Oncol 108: 123-127, 2013.

9 Douglas S, Schild SE and Rades D: Metastatic spinal cord compression in patients with cancer of unknown primary. Estimating the survival prognosis with a validated score. Strahlenther Onkol 188: 1048-1051, 2012.

10 Rades D, Douglas S and Schild SE: A validated survival score for breast cancer patients with metastatic spinal cord compression. Strahlenther Onkol 189: 41-46, 2013.

11 Rades D, Sehmisch L, Bajrovic A, Janssen S and Schild SE: Comparison of $20 \times 2$ Gy and $12 \times 3$ Gy for whole-brain irradiation of multiple brain metastases from malignant melanoma. In Vivo 30: 917-919, 2016.

12 Janssen S, Kaesmann L, Rudat V and Rades D: A scoring system for predicting the survival prognosis of patients receiving stereotactic body radiation therapy (SBRT) for 1-3 lung metastases. Lung 194: 631-635, 2016.

13 Rades D, Janssen S, Veninga T and Schild SE: Potential impact of the overall treatment time on outcomes after whole-brain irradiation with $10 \times 3$ Gy for brain metastases. Anticancer Res 36: 3071-3074, 2016.

14 Dziggel L, Schild SE, Veninga T, Bajrovic A and Rades D: Clinical factors asssociated with treatment outcomes following whole-brain irradiation in patients with prostate cancer. In Vivo 31: 35-38, 2017.

15 Rades D, Huttenlocher S, Dziggel L, Blanck O, Hornung D, Mai KT, Ngo TT, Van Pham T and Schild S: A new tool to predict survival after radiosurgery alone for newly diagnosed cerebral metastases. Asian Pac J Cancer Prev 16: 2967-2970, 2015.

16 Kaplan EL and Meier P: Non parametric estimation from incomplete observations. J Am Stat Assoc 53: 457-481, 1958.
17 Vuong DA, Rades D, Le AN and Busse R: The cost-effectiveness of stereotactic radiosurgery versus surgical resection in the treatment of brain metastasis in Vietnam from the perspective of patients and families. World Neurosurg 77: 321-328, 2012.

18 Vuong DA, Rades D, van Eck AT, Horstmann GA and Busse R: Comparing the cost-effectiveness of two brain metastasis treatment modalities from a payer's perspective: stereotactic radiosurgery versus surgical resection. Clin Neurol Neurosurg 115: 276-284, 2013.

19 Ampil F, Ellika S, Nanda A and Vora M: Long-term survival after stereotactic radiosurgery of brain metastases: A case series with 10-year follow-up. Anticancer Res 37: 5113-5115, 2017.

20 Rades D, Huttenlocher S, Hornung D, Blanck O, Schild SE and Fischer D: Do patients with very few brain metastases from breast cancer benefit from whole-brain radiotherapy in addition to radiosurgery? Radiat Oncol 9: 267, 2014.

21 Dziggel L, Dahlke M, Janssen S, Hornung D, Blanck O, Khoa MT, Schild SE and Rades D: Predicting the risk of new cerebral lesions after stereotactic radiosurgery (SRS) for brain metastases from breast cancer. Anticancer Res 35: 6793-6797, 2015.

22 Huttenlocher S, Dziggel L, Hornung D, Blanck O, Schild SE and Rades D: A new prognostic instrument to predict the probability of developing new cerebral metastases after radiosurgery alone. Radiat Oncol 9: 215, 2014.

23 Huttenlocher S, Sehmisch L, Schild SE, Blank O, Hornung D and Rades D: Identifying melanoma patients with 1-3 brain metastases who may benefit from whole-brain irradiation in addition to radiosurgery. Anticancer Res 34: 5589-5592, 2014.

Received November 28, 2017

Revised December 10, 2017

Accepted December 11, 2017 